\title{
Research Progress of wet FGD process with waste marble Hui-zhou WANG ${ }^{1, a}$, Lei LIAO ${ }^{1, b}$, Wen-xiu HU ${ }^{1, c}$ \\ ${ }^{1}$ Guilin University of Technology \\ awxfs456@163.com,, fangqiu2001@163.com, ${ }^{\mathrm{c}}$ 1393572550@qq.com
}

\section{Keywords: Marble.SO $\mathrm{SO}_{2}$. Wet Flue Gas Desulfurization}

Abstract. Marble powder is produced during the production of marble waste, the Chemical compositions of marble wastes were comparable with limestones. Therefore, the marble powder can be used instead of limestone flue gas desulfurization. In view of these, the marble powder can be alternative sorbent in WFGD. This paper reviews the research of the wet flue gas desulfurization of marble powder in lieu of limestone, including the advantages of marble powder and the benefits of using marble powder for environmental protection. At last, the problems and future prospects of flue gas desulfurization in the actual production process using marble powder are discussed.

\section{Introduction}

China's energy structure is dominated by coal, the $\mathrm{SO}_{2}$ in the flue gas of thermal power plant is the main component of air pollution, which has the characteristics of high $\mathrm{SO}_{2}$ concentration and large amount of flue gas, and is also the main material to form acid rain[1].Acid rain not only seriously corrodes buildings and public facilities, but also destroys large areas of forests and crops, so the removal of sulfur in the exhaust gas is a very important issue in flue gas treatment [2-3].

Flue gas desulfurization technology can be divided into Wet Flue Gas Desulfurization、Dry Flue Gas Desulfurization and Semi-dry Flue Gas Desulfurization. Wet Flue Gas Desulfurization technology with high desulfurization efficiency, technology maturity and other characteristics, has been widely promoted[4].At present, the world has developed wet flue gas desulfurization technology, mainly limestone-gypsum FGD, double-alkali FGD, sea water FGD, ammonia FGD, magnesium oxide FGD. According to the International Energy Agency Coal Research Organization statistics, WFGD accounted for the world's total installed capacity of FGD unit 85\%, which limestone-gypsum FGD accounted for $36.7 \%$, the other FGD technology accounted for about $48.3 \%[5]$.

\section{Principle of wet flue gas desulfurization}

Wet flue gas desulfurization technology proposed by the Royal Chemical Industry Corporation, the technology of limestone as a desulfurization absorber, the flue gas and limestone slurry contact, the 
$\mathrm{SO}_{2}$ and $\mathrm{CaCO}_{3}$ reaction generated $\mathrm{CaSO}_{3}, \mathrm{CaSO}_{3}$ is oxidized by air. The final product is $\mathrm{CaSO}_{4}$. This process is divided into six stages[6]: (1) $\mathrm{SO}_{2}$ is diffused from the gaseous phase to the gas phase side of the gas-liquid two-phase interface; (2) $\mathrm{SO}_{2}$ dissolves at the two-phase interface and enters the liquid phase; (3) $\mathrm{SO}_{2}$ ionization, generation of $\mathrm{SO}_{3}{ }^{2-}$ and $\mathrm{HSO}_{3}{ }^{-}$; (4) $\mathrm{CaCO}_{3}$ dissolved, ionized; (5) Generate calcium sulfite; (6) $\mathrm{CaSO}_{3}$ oxidized by oxygen into $\mathrm{CaSO}_{4}$ The overall reaction of post-combustion $\mathrm{SO}_{2}$ control by this slurry is:

$\mathrm{SO}_{2}+\mathrm{H}_{2} \mathrm{O} \rightarrow \mathrm{H}_{2} \mathrm{SO}_{3} \rightarrow \mathrm{H}^{+}+\mathrm{HSO}_{3}^{-}$

$\mathrm{HSO}_{3}{ }^{-} \rightarrow \mathrm{H}^{+}+\mathrm{SO}_{3}{ }^{2-}$

$\mathrm{CaCO}_{3}+2 \mathrm{H}^{+} \rightarrow \mathrm{Ca} 2+\mathrm{H}_{2} \mathrm{O}+\mathrm{CO} 2$

$\mathrm{Ca}^{2+}+\mathrm{SO}_{3}{ }^{2-} \rightarrow \mathrm{CaSO}_{3}$

$\mathrm{HSO}_{3}{ }^{-}+1 / 2 \mathrm{O}_{2} \rightarrow \mathrm{H}^{+}+\mathrm{SO}_{4}{ }^{2-}$

$\mathrm{Ca}^{2+}+\mathrm{SO}_{4}{ }^{2-}+2 \mathrm{H}_{2} \mathrm{O} \rightarrow \mathrm{CaSO}_{4}-2 \mathrm{H}_{2} \mathrm{O}$

Calcium carbonate-based calcareous stone waste powder can be used as wet flue gas desulfurization agent, because the wet flue gas desulfurization process is mainly the use of limestone $\left(\mathrm{CaCO}_{3}\right)$, lime $(\mathrm{CaO})$ or sodium carbonate $\left(\mathrm{Na}_{2} \mathrm{CO}_{3}\right)$ and other slurry for washing and the flue gas is washed in the reaction column to remove $\mathrm{SO}_{2}$ in the flue gas. The calcium carbonate-based calcareous stone waste powder contains a lot of $\mathrm{CaCO}_{3}$, and because the stone waste powder contained in the calcium carbonate composition particle size is relatively small, with a large specific surface area, can improve the efficiency of flue gas desulfurization, to Waste disposal purposes [7].

\section{Research status}

N. Emre Altun make scientific researches on chemical composition, specific surface area, grindability, reactivity of five different marble waste powders. And compared with the three limestone used in the wet flue gas desulfurization system. The results show that marble and limestone have similar chemical composition. The solubility of marble and the ability to absorb $\mathrm{SO}_{2}$ is related to the content of calcite and dolomite. Therefore, the marble has the ability to replace limestone for flue gas desulfurization [8].

The calcium hydroxide from the by-products of the marble has large specific surface area and larger pores. These larger pores facilitate the entry of gaseous $\mathrm{SO}_{2}$ into the interior of the particles to ensure a better reaction with the desulfurizer. The presence of a small amount of iron in the by-product of the marble increases the reactivity of $\mathrm{CaO}$. Therefore, the by-product of marble can be used as flue gas desulfurization agent [9]. 
Professor WU used a Rotating-Stream Tray Scrubber as a reactor to study use of marble instead of limestone for wet flue gas desulfurization and analyzed the mechanism of $\mathrm{SO}_{2}$ mass transfer reaction. The effects of different liquid/gas ratio, Inlet $\mathrm{SO}_{2}$ concentration and other major parameters on the desulfurization rate. The results showed that the optimum reaction conditions were as follows: $\mathrm{pH}=5.5 \sim 6.5$, liquid/gas ratio $=3 \mathrm{~L} / \mathrm{m}^{3}, 2 \%$ of the slurry, desulfurization efficiency of more than $60 \%$ with the best economic efficiency [10].

Chang Jing found in the use of marble waste powder flue gas desulfurization should pay attention to the flow of $\mathrm{SO}_{2}$. Excessive $\mathrm{SO}_{2}$ flow is not conducive to absorption and purification of $\mathrm{SO}_{2}$; Too low gas flow may clog the pipeline. High concentration of slurry will not only lead to blockage of the pipeline, but also affect the desulfurization efficiency. The results showed that the optimum reaction conditions were as follows: the gas flow rate was $200 \mathrm{ml} / \mathrm{min}$, slurry $\mathrm{pH}=5.5$, the marble slurry concentration was $10 \%$. In this optimum process conditions, the desulfurization rate can reach $99.85 \%$ [11].

Nan-Sheng Sheng use of marble waste powder for industrial desulfurization experiments. The experimental results show that the desulfurization efficiency of marble powder is up to standard. The low content of calcium carbonate in the desulfurized gypsum proved that the reaction activity of marble powder and sulfur dioxide is higher and the reaction degree is higher. It can be used to save the amount of desulfurizer and improve the quality of by-product gypsum [12].

\section{Problems and Prospect}

Global stone industry production 2.5 tons of finished stone products, will produce 1 ton of stone waste slurry. At present, Stone waste treatment and utilization of relatively low level, a large amount of cultivated land was occupied by Marble waste, so that water and air are polluted. Especially in the past 10 years, with the rapid development of stone production, the quantity of waste is increasing. Waste to treasure has become the top priority for environmental protection department. The main features of the marble waste powder are: (1) the marble waste powder has a large specific surface area, can be better reaction with $\mathrm{SO}_{2}$; (2) some marble waste powder with high content of calcite, is conducive to the dissolution of marble; (3) Marble has high whiteness, the gypsum produced by desulfurization has good white color, it is easy to recycle. Therefore, the recycling of stone waste, not only can save resources, reduce environmental pollution, but also has important practical significance to the sustainable development of stone industry.

In the stone cutting process, in order to prevent the coolant from high concentration slurry and affect the service life of the saw, It is necessary to add flocculant in the coolant, flocculants can accelerate the flocculation precipitation of marble powder in the coolant. Scanning electron 
microscope results showed that the waste marble powder agglomeration is more serious [13]. It is necessary to solve the problem that the effect of flocculant on marble slurry.

\section{Acknowledgements}

This research was financially supported by the National Natural Science Foundation (51468011) .

\section{References}

[1] Chunbo Wang. Operation and Control of Limestone Wet Flue Gas Desulfurization Unit for Power Plant. (2005). In Chinese.

[2] Zhu J L,Wang Y H,Zhang J C,et al. Experimental investigation of adsorption of $\mathrm{NO}$ and $\mathrm{SO}_{2}$ on modified activated carbon sorbent from flue gases[J]. Energy Convers Manage, Vol. 46 (2015), p.73-84.

[3] Gómez A,Fueyo N,Tomás A. Detailed modelling of a flue-gas desul- furization plan. Comput Chem Eng, Vol. 31 (2007), p.19-31.

[4] Lina Zuo,Qianfeng He,Dehua Liu. Progress in research on technology for wet flue gas desulfurization[J]. Environmental Engineering, Vol. S1 (2013),p. 412-416. In Chinese.

[5] Rochelle G T,et al.Chem.Eng.Prog.(1978),65-7.

[6] Tuyu Chen. Experimental study on the promoting dissolution of limestone and strengthening $\mathrm{SO}_{2}$ absorption by WFGD additives. Zhejiang University,(2013). In Chinese.

[7] Chuanfu Zhou. Study on the treatment of Wastewater from sulfur Chemicals by using Waste Stone Powder and Utilization of its By-product. South China University of Technology,(2011). In Chinese.

[8] N.Emre Altun. Assessment of marble waste utilization as an alternative sorbent to limestone for $\mathrm{SO}_{2}$ control. Fuel Processing Technology,(2014),461-470.

[9] P. Davini, Investigation into the desulphurization properties of by-products of the manufacture of white marbles of Northern Tuscany, Fuel. 79 (11) (2000)1363-1369.

[10]Zhongbiao WU,Yue Liu,Shiain YU, et al.. Experimental Study on Wet Flue Gas Desulfurization Process of Waste Marble Powder. Environmental Science,Vol.01(2002),p. 35-38. In Chinese.

[11]Jing Chang. Study on the Utilization of Marble Waste. Kunming University of Science and Technology,(2007). In Chinese.

[12] Nansheng Shen,Jian Zhang,Bingzhen Lin, et al. Application of Marble Powder to Thermal Desulfurizer in Thermal Power Plant. Fuiian building materials,2015,11:1-4. In Chinese.

[13] Songwei Lin. Study on the Use of Nanfang Waste Marble Powder as Cement Mixture. Chinese Journal of Building Materials, Vol.03(2014),p.42-45. 